\title{
Sex Differences on Elementary Cognitive Tasks Despite No Differences on the Wonderlic Personnel Test
}

Bryan Pesta

b.pesta@csuohio.edu

S. Bertsch

Peter J. Poznanski

Cleveland State University, p.poznanski@csuohio.edu

W.H. Bommer

Follow this and additional works at: https://engagedscholarship.csuohio.edu/bus_facpub

Part of the Organizational Behavior and Theory Commons

How does access to this work benefit you? Let us know!

Publisher's Statement

NOTICE: this is the author's version of a work that was accepted for publication in Personality and Individual Differences. Changes resulting from the publishing process, such as peer review, editing, corrections, structural formatting, and other quality control mechanisms may not be reflected in this document. Changes may have been made to this work since it was submitted for publication. A definitive version was subsequently published in Personality and Individual Differences, 45, 5, (2008); 10.1016/j.paid.2008.05.028

\section{Original Published Citation}

Pesta, B., Bertsch, S., Poznanski, P., Bommer, W. H. (2008). Sex Differences on Elementary Cognitive Tasks Despite No Differences on the Wonderlic Personnel Test. Personality and Individual Differences, 45(5), pp. 429-431.

This Article is brought to you for free and open access by the Monte Ahuja College of Business at EngagedScholarship@CSU. It has been accepted for inclusion in Business Faculty Publications by an authorized administrator of EngagedScholarship@CSU. For more information, please contact library.es@csuohio.edu. 


\title{
Sex differences on elementary cognitive tasks despite no differences on the Wonderlic Personnel Test
}

\author{
Bryan J. Pesta ${ }^{\mathrm{a}, *}$, Sharon Bertsch ${ }^{\mathrm{b}}$, Peter J. Poznanski ${ }^{\mathrm{c}}$, William H. Bommer ${ }^{\mathrm{d}}$ \\ ${ }^{a}$ Department of Management, Cleveland State University, 2121 Euclid Avenue, Cleveland, $\mathrm{OH} 44115$, United States \\ ${ }^{\mathrm{b}}$ Department of Psychology, University of Pittsburgh at Johnstown, Johnstown, PA 15904, United States \\ 'Department of Accounting, Cleveland State University, Cleveland, $\mathrm{OH} 44115$, United States \\ ${ }^{\mathrm{d}}$ Department of Management, California State University, Fresno, CA 93740, United States
}

\section{Introduction}

The debate over whether males and females differ in general mental ability (GMA) is again playing out in the literature. Results, however, are mixed. Some authors currently report no sex difference in GMA (Camarata \& Woodcock, 2006; Keith, Reynolds, Patel, \& Ridley, 2008). Others argue that males show a small but significant GMA advantage (Jackson \& Rushton, 2006; Lynn \& Irwing, 2008). Further complicating the issue is the large array of specific cognitive abilities showing sex differences (see, e.g., Halpern, 2000), and how these effects might differ across the lifespan (Keith et al., in press; Lynn, 1999).

A problem with using standardized IQ tests to study sex differences in GMA is that the tests themselves are constructed to minimize these differences (Neisser et al., 1996). Items showing large male/female differences are removed from the exam (Jensen, 1998). The end result is a sex-neutral test, at least at the item level. Conclusions about sex differences in GMA are therefore suspect when standardized IQ tests are used as the indicators. Our goal is to present data on the existence of sex differences on alternate measures of GMA, namely, performance on elementary cognitive tasks (ECTs). ECTs represent a range of tasks where participants perform simple cognitive acts (like judging line lengths), yet performance on them correlates moderately highly with scores on standardized IQ tests.

We therefore measured performance on two, well-researched ECTs: the inspection time (IT) and reaction time (RT) tasks (see, e.g., Jensen, 1998). In the former, participants see two vertical lines displayed briefly on a computer monitor. One line, selected randomly, is longer than the other. The subject's task is to indicate which line was longer. IT is defined as the shortest duration the lines can be displayed where a person still performs at some desired level of accuracy. Scores on IT tasks correlate about .50 with measures of GMA (for meta-analytic reviews, see Grudnik \& Kranzler, 2001; Kranzler \& Jensen, 1989). For the RT task, we show participants a computer display containing three letters (always two "S's" and one "A"). The task is to quickly and accurately indicate the position of the target letter ("A"). Typically, both RT, and the standard deviation of RT (i.e., within-persons, across trials), correlate around .50 with scores on IQ tests (Deary, Der, \& Ford, 2001; Jensen, 1992).

Regarding predictions about sex differences on ECTs, results are mixed across the few studies we found that report these data. Bonney et al. (2006) showed longer IT scores for males, but the sample comprised 70 year olds with mild cognitive impairment. Conversely, Codorniu-Raga and Vigil-Colet (2003) reported shorter IT scores for males in a sample of 11-14 year olds (see also Sheppard \& Vernon, 2008). Finally, Burns and Nettelbeck (2005) report no differences in IT, using a sample of college students. 
The pattern of sex differences for RT-based measures is more complex, and depends on the type of mental speed being assessed (for a recent review, see Sheppard \& Vernon, 2008). While it appears that females have an advantage on processing speed as measured by standardized tests like the Woodcock-Johnson III (Camarata \& Woodcock, 2006; Keith et al., in press), males seem to perform better on ECT-based measures of RT (Sheppard \& Vernon, 2008). Certainly, more research is needed on both RT and IT before any strong conclusions are warranted. Thus, we ran a sample of college students on both the IT and RT tasks. We also administered the Wonderlic Personnel Test (WPT) as a measure of GMA. We were interested in whether sex differences would appear on the ECTs, even in the absence of sex differences on the WPT.

\section{Method}

\subsection{Participants}

The participants were 218 male and 226 female undergraduates. The sample included only students who self-reported their race as "white". Further, although $84 \%$ of our participants were under age 30, a small mean age difference appeared, as males ( $M=24.25$ years) were 1.78 years older on average than were females $(M=22.47$ years; $t(442)=3.31)$. Hence, we controlled for age effects below (which weakened the sex difference on the WPT/IQ test, but strengthened it for the ECTs).

\subsection{Materials and procedure}

We selected the WPT as our measure of general mental ability. The WPT is a paper-and-pencil exam used widely in employment settings. It features a population mean of 22 with a population standard deviation of seven. Research shows reliabilities for the WPT ranging from .82 to .94 (Geisinger, 2001). The test manual reports correlations between the WPT and the Wechsler adult intelligence scale revised ranging from .75 to .96 (Wonderlic, 2002; see Table 9, p. 34).

We administered the 12 min version of the exam to groups of students in classroom settings. Students later completed the ECTs in our labs, using standard desktop computers with cathode ray tube monitors. The computer sessions lasted about $15 \mathrm{~min}$ for each participant.

Complete details on stimulus presentation and timing issues for the IT and RT tasks appear in Pesta and Poznanski (2008). Briefly here, trials began with a blank computer screen, followed by a fixation cross. For the IT task, two vertical lines appeared, joined at the top by a horizontal line. One of the vertical lines, selected at random, was longer than the other. The lines remained on-screen for varying amounts of time across trials, and were then replaced by a pattern mask. In general, the duration of the line display decreased with correct answers (making the task more difficult) and increased with incorrect answers (making the task less difficult). On each trial, students pressed the " $z$ " key if they thought the left line was longer than the right line, or the "I" key if they thought the opposite. We stressed that speed of response was not important for this task, and that students should instead focus only on accuracy. The values we report here for the IT task are the average display durations for each subject across 95 trials (with lower numbers indicating better IT performance).

For trials in the RT task, a display appeared containing three letters (e.g., SAS), which remained on-screen until response. Participants quickly indicated the position the target letter (i.e., A) appeared in, by pressing the appropriate number (i.e., 1, 2, or 3) on the number pad of the keyboard. We told students to respond fast, while maintaining high accuracy levels. Values reported for this task include each subject's median RT, and his/her standard deviation of RT, across 60 trials.

\section{Results}

Table 1 shows descriptive statistics and tests of mean differences by sex for the study variables. All sex differences in the table were significant, except for scores on the WPT $(t(442)=1.80$, $p=.073$ ). Note that females had significantly higher GPAs, but males scored better on all ECT measures. The last row in Table 1 is an ECT factor score derived from a principal axis factor analysis on the three ECT variables. The factor explained $54.1 \%$ of the ECT variance, with loadings of .58, .74, and .37, for RT median, RT standard deviation, and IT, respectively. Perhaps because factor scores are more reliable than the individual measures that contribute to them, it produced the largest effect size in the table $(d=-.38)$.

Table 2 shows simple correlations for the study variables, after controlling for age. Consistent with the Table 1 data, sex correlated near zero with the WPT, but showed small, significant relationships with all other variables in the table. As mentioned above, controlling for age weakened the relationship between sex and the WPT $(r=-.09$ and -.03 before and after age correction, respectively). Conversely, sex differences on the ECT measures increased slightly after partialing out age. For example, the correlation between sex and the ECT composite was -.18 before age correction and -.21 after.

Finally, although technically not a test of mediation (as the sex difference on the WPT was non-significant), we also looked at sex differences on the ECT factor score when controlling for the WPT, and vice versa. The sex difference on the ECT score remained significant, even when WPT scores were partialled out $(r=.21$ before controlling for the WPT, and $r=.17$ after-smaller numbers on the ECT factor score indicate better performance). The WPT, however, correlated only -.04 with sex, when controlling for ECT.

Table 1

Means and standard deviations for the study variables by sex

\begin{tabular}{lllll}
\hline Variable & Sex & & \\
\cline { 2 - 5 } & Males & Females & Difference & Effect size $^{\text {a }}$ \\
\hline Age in years & $24.25(5.5)$ & $22.47(5.8)$ & $1.78^{*}$ & .31 \\
Grade point average & $3.00(.60)$ & $3.22(.61)$ & $-0.22^{*}$ & -.36 \\
Wonderlic IQ & $24.70(4.8)$ & $23.81(5.5)$ & 0.89 & .17 \\
RT median & $448.85(55.1)$ & $463.31(56.6)$ & $-14.46^{*}$ & -.26 \\
RT standard deviation & $68.59(17.1)$ & $74.43(21.5)$ & $-5.84^{*}$ & -.30 \\
Inspection time & $94.60(57.3)$ & $120.68(90.7)$ & $-26.08^{*}$ & -.34 \\
ECT factor score & $-0.15(0.71)$ & $0.15(.87)$ & $-0.30^{*}$ & -.38 \\
\hline
\end{tabular}

Notes: $n=218$ for males and $n=226$ for females. RT median, RT standard deviation and inspection time were measured in milliseconds (smaller numbers indicate better performance).

a Cohen's $d$, using the pooled group standard deviation. $* p<.05$.

Table 2

Simple correlations for the study variables, after controlling for age

\begin{tabular}{llllllll}
\hline Measure & 1 & 2 & 3 & 4 & 5 & 6 & 7 \\
\hline Sex & - & $.18^{*}$ & -.03 & $.15^{*}$ & $.18^{*}$ & $.16^{*}$ & $.21^{*}$ \\
Grade point average & & - & $.20^{*}$ & -.04 & .00 & -.03 & .03 \\
Wonderlic IQ & & & - & $-.22^{*}$ & $-.27^{*}$ & $-.26^{*}$ & $-.32^{*}$ \\
Inspection time & & & & - & $.26^{*}$ & $.29^{*}$ & $.48^{*}$ \\
RT median & & & & & - & $.44^{*}$ & $.72^{*}$ \\
RT standard deviation & & & & & & - & $.92^{*}$ \\
ECT factor score & & & & & & & - \\
\hline
\end{tabular}

Notes: Age in years was first partialled out of all correlations in the table. Sex is coded as 0 for males and 1 for females. For all ECT variables and the factor score, smaller numbers indicate better performance. ${ }^{*} p<05$. 
Hence, small but reliable sex differences seem to exist both on IT and RT, even without sex differences on a standardized IQ test.

\section{Discussion}

Our goal was to show that standardized IQ tests may mask true sex differences in GMA, as these tests are constructed to minimize male/female score differences. ECTs, on the other hand, do not suffer from this complication. Further, ECTs break from traditional "standardized test" approaches to studying intelligence by measuring performance at the level of basic cognitive processes. As such, ECTs possess construct validity as measures of GMA (see Jensen, 1998; Jensen, 2006).

We found small but reliable sex differences on both the IT and RT tasks. Jackson and Rushton (2006) estimated a 3.63 point IQ difference in favor of males (using g-factor scores derived from scholastic aptitude test performance). Looking at our data with ECTs as a proxy for GMA, effect sizes ranged from .26 (for reaction time) to .38 (for the factor score), again favoring males. Translating these effects to IQ points (with a mean of 100 and standard deviation of 15) reveals a male/female difference of between 3.9 and 5.7 points. These values are somewhat higher but not inconsistent with those Jackson and Rushton (2006) report.

Limitations to the present study include: (1) the use of only a narrow set of ECTs, versus a full battery. Whether sex differences would appear on other varieties of ECTs (e.g., auditory IT, or RT measured with the Hick task) remains therefore unknown. (2) The correlation between our ECT factor score and the WPT IQ test $(r=-.32)$ was smaller than that typically seen in the literature (around $r=-.50$ in meta-analyses). Meta-analyses, however, typically correct for range restriction, whereas we did not. Further, we speculate that future research using more ECTs and more trials per ECT would increase reliability, and perhaps result in correlations more consistent with those reported in the meta-analytic literature. (3) The sample we employed was restricted to white, young, college students.

In sum, though our data need replication with a more diverse sample of ECTs and participants, we believe a small but reliable sex difference exists on GMA measured via ECTs, but not on GMA measured via IQ tests. We argue the present data show the poten- tial that ECTs may have for revealing and clarifying sex differences in GMA

\section{References}

Bonney, K., Almeida, O., Flicker, L., Davies, S., Clarnette, R., Anderson, M., et al. (2006). Inspection time in non-demented older adults with mild cognitive impairment. Neuropsychologia, 44, 1452-1456.

Burns, N., \& Nettelbeck, T. (2005). Inspection time and speed of processing: Sex differences on perceptual speed but not IT. Intelligence, 39, 439-446.

Camarata, S., \& Woodcock, R. (2006). Sex differences in processing speed: Developmental effects in males and female. Intelligence, 34, 231-252.

Codorniu-Raga, M., \& Vigil-Colet, A. (2003). Sex differences in psychometric and chronometric measures of intelligence among young adolescents. Personality Individual Differences, 35, 681-689.

Deary, I., Der, G., \& Ford, G. (2001). Reaction time and intelligence differences: A population based cohort study. Intelligence, 29, 389-399.

Geisinger, K. (2001). Review of the Wonderlic personnel test and scholastic level exam. In B. S. Plake \& J. C. Impara (Eds.), The fourteenth mental measurements yearbook (pp. 1360-1363). Lincoln, NE: The Buros Institute of Mental Measurements.

Grudnik, J., \& Kranzler, J. (2001). Meta-analysis of the relationship between intelligence and inspection time. Intelligence, 29, 523-535.

Halpern, D. (2000). Sex differences in cognitive abilities. Philadelphia, PA: Erlbaum \& Associates.

Jackson, D., \& Rushton, J. (2006). Males have greater g: Sex differences in general mental ability from 100,000 17- to 18-year olds on the scholastic assessment test. Intelligence, 34, 479-486.

Jensen, A. (2006). Clocking the mind: Mental chronometry and individual differences. Amsterdam, The Netherlands: Elsevier.

Jensen, A. (1998). The $g$ factor: The science of mental ability. Westport, CT: Praeger.

Jensen, A. (1992). The importance of intraindividual variation in reaction time. Personality Individual Differences, 13, 869-881.

Keith, T., Reynolds, M., Patel, P., \& Ridley, K. (in press). Sex differences in latent cognitive abilities ages 6 to 59: Evidence from the Woodcock-Johnson III tests of cognitive abilities. Intelligence.

Kranzler, J., \& Jensen, A. (1989). Inspection time and intelligence: A meta-analysis. Intelligence, 13, 329-347.

Lynn, R. (1999). Sex differences in intelligence and brain size: A developmental theory. Intelligence, 27, 1-12.

Lynn, R., \& Irwing, P. (2008). Sex differences in mental arithmetic, digit span, and g defined as working memory capacity. Intelligence, 36, 226-235.

Neisser, U., Boodoo, G., Bouchard, T., Boykin, W., Brody, N., Ceci, S., et al. (1996). Intelligence: Knowns and unknowns. American Psychologist, 51, 77-101.

Pesta, B., \& Poznanski, P. (2008). Black/white differences on intelligence and grades: The mediating role of elementary cognitive tasks. Intelligence, 36, 323-329.

Sheppard, L., \& Vernon, P. (2008). Intelligence and speed of information-processing: A review of 50 years of research. Personality Individual Differences, 44, 535-551.

Wonderlic \& Associates (2002). Wonderlic personnel test manual. Libertyville, IL: Wonderlic. 